\title{
EVALUASI PROGRAM PENDIDIKAN AGAMA ISLAM MENGGUNAKAN MODEL EVALUASI CIPP
}

\author{
Aris Try Andreas Putra \\ Institut Agama Islam Negeri (IAIN) Kendari \\ aristryandreasputra@gmail.com \\ Rianti Zarita \\ Institut Agama Islam Negeri (IAIN) Kendari \\ riantizarita@gmail.com \\ Nurhafidah \\ Institut Agama Islam Negeri (IAIN) Kendari \\ nurhafidah@gmail.com
}

\begin{abstract}
Abstrak
Artikel ini akan membahas tentang evaluasi program pendidikan agama Islam dengan menggunakan model evaluasi CIPP. Kajian penulisan artikel menggunakan kajian literature. Adapun hasil pembahasan adalah sebagai berikut: 1) Model CIPP (Context, Input, Proses, Product) adalah model evaluasi yang dikembangkan oleh Daniel Stufflebeam di Ohio State University. Keempat model evaluasi tersebut merupakan satu rangkaian yang utuh. Akan tetapi Stufflebeam mengatakan bahwa pelaksanaannya seorang evaluator tidak harus menggunakan keseluruhannya. Keunikan pada model-model tersebut adalah pada setiap tipe evaluasi terkait dengan perangkat pengambilan keputusan dan operasi sebuah program. 2) program pendidikan agama Islam dapat dievaluasi mengguanakan model CIPP, 3) dengan menggunakan evaluasi CIPP program pendidikan agama Islam dapat menunjukan beberapa aspek, yaitu sisi konteks, input, proses dan produk.
\end{abstract}

Kata Kunci: Evaluasi Program PAI; Model Evaluasi CIPP

\begin{abstract}
This article will discuss the evaluation of Islamic religious education programs using the CIPP evaluation model. The study of article writing uses a literature review. The results of the discussion are as follows: 1) The CIPP (Context, Input, Process, Product) model is an evaluation model developed by Daniel Stufflebeam at Ohio State University. The four evaluation models are a complete series. However, Stufflebeam says that in its implementation an evaluator does not have to use the whole thing. The uniqueness of these models is that each type of evaluation is related to the decisionmaking tools and operation of a program. 2) Islamic religious education programs can be evaluated using the CIPP model, 3) using the CIPP evaluation Islamic religious education programs can show several aspects, namely the context, input, process and product.
\end{abstract}

Keywords: Program Evaluation; CIPP Evaluation Model. 


\section{A. Konsep Dasar Evaluasi Program}

Dari awal perkembangannya evaluasi pendidikan sekitar tahun 1960-an sampai sekarang, tokoh-tokoh evaluasi telah mengembangkan sekitar raham bentuk-bentuk evaluasi (Putra, Evaluasi Program Pendidikan Pedekatan Evaluasi Program Berorientasi Tujuan (Goal-Oriented Evaluation Approach Ralph W Tyler), 2012). Berbagai model ini pula didasarkan pada pendekatan, bentuk-bentuk dan tujuan evaluasi. Evaluasi program merupakan kegiatan sistematis melakukan penilaian dan pengukuran terhadap objek kajian. (Musa, 2005) Evaluasi program merupakan suatu kegiatan untuk memperoleh gambaran tentang keadaan suatu objek yang dilakukan secara terencana, sistematik dengan arah dan tujuan yang jelas. Evaluasi program dilakukan sebagai upaya untuk mengumpulkan, menyusun, mengolah dan menganalisis fakta, data dan informasi untuk mengumpulkan harga nilai evaluasi merupakan bagian yang penting dalam setiap kegiatan ataupun program, sehingga tidak ada satu kegiatan pun yang dapat terlaksana dengan baik tanpa evaluasi. Grounlund dalam (Djaali, 2004) menjelaskan bahwa evaluasi suatu proses yang sistematis untuk menentukan atau membuat keputusan sampai sejauh mana tujuan atau program telah tercapai. Oleh karena itu, evaluasi selalu berhubungan dengan pengambilan keputusan, karena hasil evaluasi merupakan suatu landasan untuk menilai suatu program dan memutuskan apakah program tersebut dapat diteruskan atau masih perlu diperbaiki lagi. Setiap pelaksanaan program, perencanaan, pengolahan dan pelaksanaan program perlu mengetahui keberhasilan dari penyelenggaran program. Dengan demikian, maka evaluasi program berfungsi sebagai pembantu, pengontrol pelaksanaan program agar dapat diketahui tindak lanjut pelaksanaan program tersebut.

Sejalan dengan itu, (Tasner, 1995) mengatakan bahwa evaluasi merupakan pengambilan data untuk menentukan harga atau nilai yang diperoleh individu secara baik atau kurang baik. Lebih lanjut dikatakan bahwa evaluasi program dilakukan untuk kepentingan pengambilan kebijakan untuk menentukan kebijakan selanjutnya. Dalam melakukan evaluasi program tidak bisa dilakukan secara serampangan, tetapi sistematis, rinci dalam menggunakan prosedur yang sudah diuji secara cermat. Dengan metodemetode tertentu maka akan diperoleh data yang handal dan dapat dipercaya. Penentuan kebijakan akan tepat apabila data yang digunakan sebagai pertimbangan tersebut benar, akurat dan lengkap, karena evaluasi dapat menentukan ketercapaian sebuah program. 
Selain beberapa pendapat diatas, Anderson dalam (Suharsimi Arikunto, 2004) mengatakan bahwa evaluasi sebagai sebuah proses menentukan hasil yang telah dicapai beberapa kegiatan yang dirancang untuk mendukung tercapainya tujuan. Oleh karena itu, melakukan evaluasi program berarti melakukan kegiatan yang dimaksudkan untuk mengetahui seberapa tinggi tingkat keberhasilan dari kegiatan yang direncanakan. Lebih jauh Anderson mengatakan bahwa sebenarnya yang menjadi titik awal dari kegiatan evaluasi program adalah keingin tahuan untuk melihat apakah tujuan program sudah tercapai atau belum. Jika sudah tercapai bagaimanakah kualitas pencapaian kegiatan tersebut. Jika belum tercapai bagian manakah dari perencanaan yang telah dibuat yang belum tercapai dan apa yang menyebabkan bagian rencana tersebut belum tercapai, ataukah faktor luar. Ada berbagai pendapat lain mengenai evaluasi yang dikemukakan oleh para pakar ataupun lembaga evaluasi, antara lain dari (Popham W. J., 1981) yang menyatakan bahwa evaluasi adalah proses pencarian, pengumpulan dan pemberian data (informasi) kepada pengambil keputusan yang diperlukan untuk memberikan pertimbangan apakah program perlu diperbaiki, dihentikan atau diteruskan. Hal yang senada diungkapkan oleh (Leonora Layola Oriondo, 1998) bahwa evaluasi adalah suatu proses mengumpulkan, menganalisis dan menginterpretasikan informasi yang didapat melalui pengukuran untuk memberikan beberapa makna berdasarkan pertimbangan nilai.

Evaluasi adalah proses pengumpulan dan analisis data secara sistematis yang diperlukan dalam rangka pengambilan keputusan. Dikatakan pula oleh Worthen dan Sanders dalam Arikunto (Suharsimi Arikunto, 2004) bahwa evaluasi adalah kegiatan mencari sesuatu yang berharga tentang sesuatu, dalam mencari sesuatu tersebut termasuk informasi, produksi, prosedur serta alternatif strategi yang diajukan untuk mencapai tujuan yang ditentukan. Sehingga evaluasi akan menghasilkan umpan balik dalam kerangka efektifitas pelaksanaan kegiatan organisasi.

Sejalan dengan berbagai pengertian evaluasi yang telah dikemukakan diatas, Grounlund (Norman E. Groundlund, 1990) dalam Measurement and Evaluation in Teaching mengemukakan pula bahwa evaluasi is the systematic process of collecting, analyzing and interpreting information to determine the extent to which pupils achieving instructional objects. Jadi evaluasi adalah proses untuk mengumpulkan informasi secara sistematik, objektif untuk memberikan keputusan terhadap suatu objek. 
Menurut Worthen dan Sanders dalam Suparman (Suparman M. Atwi, 2004) evaluasi merupakan penentuan kelayakan sesuatu yang meliputi perolehan informasi untuk digunakan menilai kelayakan suatu program, produk, prosedur atau tujuan atau pendekatan-pendekatan alternatif potensial yang didesain untuk mencapai tujuan khusus.

Selanjutnya konsep evaluasi program merupakan evaluasi yang menaksir kegiatan pendidikan yang memberikan pelayanan pada suatu dasar yang kontiniu dan sering melibatkan tawaran-tawaran kurikuler. Sejalan dengan konsep evaluasi program tersebut, menurut (Rutman, 1984) evaluasi program adalah penerapan metode-metode ilmiah untuk mengukur dan hasil program untuk pengambilan keputusan. Sedangkan (Brinkerhoff, 1983) Brinkerhoff menyatakan bahwa evaluasi program adalah :

1. proses menentukan sejauh mana tujuan dan sasaran program telah terealisasi

2. memberikan informasi untuk pengambilan keputusan

3. perbandingan kinerja dengan patokan-patokan tertentu untuk menentukan apakah terdapat kesenjangan

4. penilaian tentang harga dan kualitas

5. ukuran, pilih yang dikembangkan, dengan itu masing-masing tujuan ditentukan dan

6. investigasi sistematis mengenai nilai atau kualitas suatu objek.

Isaac dan William dalam (Suparman M. Atwi, 2004) menyatakan bahwa evaluasi program menyandarkan dan mewujudkan tiga rangkaian tahapan yaitu :

1. Tujuan, nyatakan secara jelas dan spesifik masing-masing tujuan satu term yang bisa diukur dan diamati

2. Sarana, rencanakan berbagai strategi dan aktivitas yang akan dilaksanakan untuk mencapai masing-masing tujuan

3. Ukuran, pilih dan kembangkan ukuran-ukuran yang dengan itu masing-masing tujuan akan ditentukan.

Menurut (Rutman, 1984), evaluasi program adalah penerapan metode-metode ilmiah untuk mengukur implementasi dari hasil program untuk pengambilan keputusan. Sedangkan Bigman berpendapat bahwa ada beberapa pemakaian evaluasi program, yaitu:

1. Untuk menemukan apakah tujuan dapat dicapai dan sebarapa jauh dapat dicapai 
2. Untuk menemukan alasan keberhasilan dan kegagalan secara khusus tujuan suatu program.

3. Untuk menemukan prinsip yang melandasi keberhasilan program.

4. Untuk melakukan eksperimen-eksperimen dengan teknik-teknik tertentu guna meningkatkan efektifitas .

5. Untuk meletakkan dasar guna melakukan penelitian lanjut atas dasar keberhasilan alternatif teknik yang digunakan.

6. Untuk merumuskan kembali cara yang akan digunakan dalam mencapai tujuan dan bahkan merumuskan kembali sub tujuan sesuai dengan temuan penelitian.

Menurut (Syah, Psikologi Pendidikan dengan Pendekatan Baru , 1995), tujuan evaluasi bidang pendidikan adalah pertama mengetahui tingkat kemampuan yang telah dicapai siswa dalam suatu kurun waktu proses belajar tertentu, kedua untuk mengetahui posisi atau kedudukan seorang siswa dalam kelompok kelasnya, ketiga untuk mengetahui tingkat usaha yang dilakukan siswa dalam belajar, keempat untuk mengetahui hingga sejauh mana siswa telah mendayagunakan kapasitas kognitifnya, kelima untuk mengetahui tingkat daya guna dan hasil guna metode mengajar yang telah digunakan guru dalam proses belajar mengajar.

Menurut (Thorndike R.L, 1991) Tujuan evaluasi dalam kependidikan mencakup delapan bidang, yaitu untuk pembelajaran, hasil belajar, diagnosis dan usaha perbaikan, fungsi penempatan, fungsi seleksi, bimbingan dan penyuluhan, kurikulum dan penilaian kelembagaan. Menurut (Toha, 1991) Evaluasi dari pendekatan proses adalah untuk mengetahui apakah tujuan pendidikan sudah tercapai dan untuk memperbaiki serta mengarahkan pelaksanaan proses belajar mengajarnya. Selanjutnya, (Toha, 1991) dari pendekatan kelembagaan, maka kegiatan pendidikan merupakan kegiatan manusia yang meliputi : penyusunan desain, pembuatan program, pengaturan, pelaksanaan pengawasan dan evaluasi.

Dari berbagai pendapat dan pengertian evaluasi program diatas, dapat disimpulkan bahwa evaluasi program adalah suatu upaya untuk mengumpulkan, menyusun, mengolah dan menganalisa fakta, data dan informasi untuk menyimpulkan harga, nilai, prestasi, kegunaan, manfaat mengenai suatu program, kantor, sekolah, organisasi atau lembaga dan lain-lain untuk dibuat kesimpulan sebagai landasan 
pengambilan keputusan tentang program tersebut, apakah dilanjutkan, direvisi atau dihentikan.

Pelaksanaan evaluasi program pendidikan untuk mengetahui tingkat ketercapaian program sekaligus untuk memberikan pertanggungjawaban (accountability) terhadap program yang telah berjalan dan memberikan informasi pada pengambil keputusan pada tahap perencanaan. Ketercapaian output pendidikan yang bermutu tidak terlepas dari proses pendidikan yang dilakukan dan merupakan perpaduan dari berbagai dimensi, baik yang berkaitan dengan input pendidikan maupun proses pendidikan itu sendiri.

Dengan demikian, evaluasi program dalam kegiatan penyelenggaraan program pendidikan agama Islam sekolah merupakan kegiatan pengumpulan, pengolahan dan penyajian data secara sistematis dalam rangka pengambilan keputusan selanjutnya terhadap program.

\section{B. Prinsip-prinsip Evaluasi Program}

a. Komprehensif, Bahwa evaluasi program harus mencakup bidang sasaran yang luas atau menyeluruh, baik aspek personalnya, materialnya, maupun aspek operasionalnya. Evaluasi Jangan hanya ditujukan pada salah satu aspek saja. Evaluasi harus dilakukan secara menyeluruh.

b. Komparatif, Prinsip ini menyatakan bahwa dalam mengadakan evaluasi program supervisi pendidikan harus dilaksanakan secara bekerjasama dengan semua orang yang terlibat dalam aktivitas program pendidikan. Dengan melibatkan semua pihak dalam evaluasi program pendidikan ini diharapkan dapat mencapai keobyektifan dalam mengevaluasi.

c. Kontinyu, Evaluasi program pendidikan hendaknya dilakukan secara terusmenerus selama proses pelaksanaan program. Evaluasi tidak hanya dilakukan terhadap hasil yang telah dicapai, tetapi sejak pembuatan rencana sampai dengan tahap laporan. Hal ini penting dimaksudkan untuk selalu dapat 
memonitor setiap saat atas keberhasilan yang telah dicapai dalam periode waktu tertentu. Aktivitas yang berhasil diusahakan untuk ditingkatkan, sedangkan aktivitas yang gagal dicari jalan lain untuk mencapai keberhasilan.

d. Obyektif. Dalam mengadakan evaluasi program pendidikan harus menilai sesuai dengan kenyataan yang ada. Katakanlah yang hijau itu hijau dan yang merah itu merah. Jangan sampai mengatakan yang hijau itu kuning, dan yang kuning itu hijau. Untuk mencapai keobyektifan dalam evaluasi perlu adanya data dan atau fakta. Dari data dan fakta inilah dapat mengolah untuk kemudian diambil suatu kesimpulan. Makin lengkap data dan fakta yang dapat dikumpulkan maka makin obyektiflah evaluasi yang dilakukan.

e. Berdasarkan Kriteria yang Valid, Selain perlu adanya data dan fakta, juga perIu adanya kriteria-kriteria tertentu. Kriteria yang digunakan dalam evaluasi harus konsisten dengan tujuan yang telah dirumuskan. Kriteria ini digunakan agar memiliki standar yang jelas apabila menilai suatu aktivitas supervisi pendidikan. Kekonsistenan kriteria evaluasi dengan tujuan berarti kriteria yang dibuat harus mempertimbangkan hakekat substansi program. Kriteria dalam evaluasi program supervisi pendidikan ada dua, yaitu pertama, kriteria objective yang berkenaan dengan patokan tujuan yang ingin dicapai. Tujuan inilah yang dijadikan kriteria keberhasilan pelaksanaanprogram supervisi pendidikan. Kedua, kriteria metodis yang berkaitan dengan patokan teknik penganalisaan hasil evaluasi: misalnya dengan menggunakan prosentase, interval, kuantitatif, atau perhitungan matematis lainnya. 
f. Fungsional, Hasil evaluasi program pendidikan berarti fungsional apabila dapat digunakan untuk memperbaiki situasi yang ada pada saat itu. Dengan demikian evaluasi program pendidikan benar-benar memiliki nilai guna baik secara langsungmaupun tidak langsung. Kegunaan langsungnya adalah dapatnya hasil evaluasi digunakan untuk perbaikan apa yang dievaluasi, sedangkan kegunaan tidak langsungnya adalah hasil evaluasi itu dimanfaatkan untuk penelitian atau keperluan lainnya.

g. Diagnostik, Evaluasi program pendidikan hendaknya mampu mengidentifikasi kekurangan-kekurangan atau kelemahan-kelemahan apa yang dievaluasi sehingga dapat memperbaikinya. Oleh sebab itu setiap hasil evaluasi program pendidikan harus didokumentasikan. Bahan-bahan dokumentasi hasil evaluasi inilah yang dapat dijadikan dasar penemuan kelemahan-kelemahan atau kekurangan-kekurangan yang kemudian harus diusahakan jalan pemecahannya. (Nasional, 2009)

\section{B. Manfaat Evaluasi Program}

Menurut (Tayibnapis, 2008) Evaluasi program bermanfaat menyampaikan pesan, memberi informasi yang tepat kepada audiensi tentang penemuannya dan kesimpulan hasil pengumpulan informasi, analisis, dan tafsiran informasi evaluasi. Cronbach seperti dikutib (Tayibnapis, 2008) mengatakan bahwa evaluasi yang baik adalah yang memberikan dampak positif pada perkembangan program. Sehingga evaluasi hendaknya dapat digunakan untuk memeriksa keberhasilan program berkaitan dengan lingkungan program dengan suatu kesimpulan apakah program dapat diteruskan, ditolak, diteruskan dengan catatan, atau sudah dapat diterapkan ditempat lain. 
(Egon G Guba, 1983) menyatakan bahwa evaluation needed to focus on the ways in which refinements and improvements could accur while the course was in process of development. Pendapat ini menyatakan bahwa evaluasi bermanfaat untuk perbaikan program dalam sebuah proses pengembangan. Jadi evaluasi dilaksanakan dengan memberikan informasi secara teliti agar dapat menjadi bahan masukan untuk pengembangan sebuah program.

Worthen menyatakan bahwa oriented approach to evaluation support evaluation of every component of an educational program as it operates, grow, or changes. Dari pernyataan tersebut, didalam sebuah program pendidikan, pendekatan evaluasi bermanfaat dalam mendukung evaluasi sebagai usaha untuk pengoperasian, pertumbuhan atau pembaharuan sebuah program. Pengoperasian, pertumbuhan atau pembaharuan program dapat diartikan sebagai pengembangan atau perbaikan dari program yang dilaksanakan.

(Daniel L Stufflebeam, 2007) menyatakan bahwa evaluation appropriately promotes and assists goal achivement and ongoing improvement. Sejalan dengan pendapat tersebut, (George F. Madaus, 1985) menyatakan bahwa evaluation is carried out in service of course improvement. Sebagai upaya dari perbaikan sebuah program, maka hasil evaluasi akan sangat bermanfaat sebagai umpan balik bagi pimpinan dan staff pelaksana dari sebuah program.

Dari berbagai pendapat tersebut di atas maka manfaat evaluasi program secara umum dapat disimpulkan bahwa evaluasi dapat bermanfaat memberikan informasi untuk perbaikan program. Dan secara khusus evaluasi program bermanfaat untuk perbaikan keputusan perencanaan dan kebutuhan, perbaikan keputusan pelayanan secara terstruktur, perbaikan pedoman dalam melaksanakan keputusan, dan memberikan 
pelayanan pengambilan keputusan ulang. Evaluasi Program Pendidikan Klinik akan bermanfaat memberikan informasi secara lengkap sebagai bahan pertimbangan pengambilan keputusan.

\section{Standar Evaluasi}

Evaluasi program akan menyajikan data objektif dan memberikan penilaian terhadap pelaksanaan program. Sehingga evaluasi memerlukan standar evaluasi agar dapat memfokuskan kegiatan evaluasi terhadap tujuan yang akan dicapai dalam pelaksanaan evaluasi program. Standar evaluasi yang jelas akan dapat mengarahkan pelaksanaan evaluasi dapat berjalan secara obyektif.

(Evaluation, 1994) Secara keseluruhan standar evaluasi program yang digunakan oleh beberapa ahli mengacu pada standar evaluasi program dari Joint Committee. Hal ini disebabkan Joint Committee sebagai sebuah organisasi yang menjadi naungan para ahli evaluasi, standar evaluasi tersebut adalah utility, feasibility, propriety, dan accuracy.

Standar kegunaan (utility) akan dibutuhkan seorang evaluator untuk menghadapi perbedaan berbagai macam klien yang berperan dengan hasil evaluasi, untuk memastikan informasi yang dibutuhkan dan untuk melaporkan informasi yang relevan terhadap klien secara jelas menyeluruh dan tepat waktu.

Pada standar kelayakan (feasibility) akan berfokus pada kelayakan dan realisasi bahwa prosedur evaluasi efektif secara biaya dan dapat diterapkan. Standar evaluasi ini memerlukan rencana evaluasi yang dapat diterapkan dalam suatu kondisi sulit sesuai nilai penelitian terhadap praktek. Sehingga memerlukan evaluasi yang realistis, bijaksana, cerdas, dan hemat. 
Standar kesesuaian (proprierty) akan menggambarkan kenyataan bahwa evaluasi dapat mempengaruhi banyak orang dalam banyak hal. Dalam standar kesesuaian ini memastikan bahwa hak seseorang yang terlibat dalam evaluasi akan dilindungi, sehingga evaluasi dapat berjalan secara legal, etis, dan dengan mempertimbangkan keselamatan terhadap keterlibatan serta efek evaluasi.

Standar ketelitian (accuracy) memerlukan suatu hasil kesimpulan informasi tepat dengan teknik yang memadai dan logika meyakinkan terhadap data. Sehingga deskripsi dari analisa data tepat dalam memberikan informasi. Sehingga dalam artikel ini juga menggunakan standar evaluasi meliputi kegunaan (utility) yaitu menyesuaikan dengan kegunaan evaluasi sesuai harapan setiap klien, kelayakan (feasibility) yaitu setiap prosedur evaluasi dapat dilaksanakan secara proporsional, kesesuaian (propriety) yaitu evaluasi dapat dilaksanakan secara legal, etis, dan aman terhadap efek evaluasi dan keterlibatan berbagai komponen, dan ketelitian (accuracy) yaitu informasi dapat disimpulkan dengan teknik dan logika yang dapat diterima.

\section{Model Evaluasi Program CIPP dalam Pendidikan Agama Islam}

Para pakar telah mendesain model-model teoritik yang dapat dipakai sebagai pedoman untuk melaksanakan evaluasi program secara sistematik. Model-model evaluasi ini menunjukkan adanya perbedaan dalam pendekatan, tetapi ini tidak berarti model yang satu lebih baik dari pada model lainnya. Bahkan dapat dikatakan bahwa tiap-tiap model mempunyai keunggulan dan kelemahannya masing-masing.

Hal-hal yang perlu diperhatikan dalam suatu program evaluasi, antara lain : (a) evaluator mengumpulkan dan menganalisis informasi yang ada, (b) evaluator mengidentifikasi standar mutlak, formal dan informal yang berhubungan dengan kelompok, (c) evaluator menyusun data data deskripsi dari program lain, dan (d) evaluator menelaah bahwa program tersebut menyatu dengan standar mutlak dan standar relatif. 
Sedangkan menurut (Popham W. J., 1974) dalam Educational Evaluation, mendeskripsikan bahwa tiga langkah utama dalam proses evaluasi model CIPP, yaitu : (1) penggambaran, yang berkenaan dengan memfokuskan informasi yang diperlukan oleh pembuat keputusan melalui penentuan, penetapan dan penegasan, (2) perolehan, berkenaan dengan pengumpulan, pengorganisasian dan penggunaan analisis informasi dengan menggunakan prosedur-prosedur teknis seperti pengukuran dan statistik, (3) pemberian, yang berkenaan dengan sintesis dari informasi secara optimal yang bermanfaat untuk tujuan evaluasi. Ketiga tahap tersebut memerlukan atau melibatkan informasi dan bagaimana informasi itu dapat dipisahkan, dikumpulkan dan dipresentasikan terhadap orang-orang yang membuat keputusan pendidikan.

(Popham W. J., 1974) Model CIPP (Context, Input, Proses, Product) adalah model evaluasi yang dikembangkan oleh Daniel Stufflebeam dan kawan-kawan di Ohio State University. Keempat model evaluasi tersebut merupakan satu rangkaian yang utuh. Akan tetapi Stufflebeam mengatakan bahwa pelaksanaannya seorang evaluator tidak harus menggunakan keseluruhannya. Keunikan pada model-model tersebut adalah pada setiap tipe evaluasi terkait dengan perangkat pengambilan keputusan dan operasi sebuah program.

Selanjutnya dijelaskan lagi (Popham W. J., 1974), bahwa model CIPP juga mengidentifikasi beberapa penyiapan keputusan yaitu (1) perencanaan keputusan untuk menentukan tujuan, (2) penyusunan keputusan untuk mendesain prosedur pembelajaran, (3) pelaksanaan keputuan menggunakan untuk memotitor dan memperbaiki prosedur, (4) mengkaji ulang keputusan untuk menetapkan dan reaksinya terhadap dampak yang dihasilkan oleh prosedur. Keempat tahapan keputusan inilah yang berhubungan dengan tipe evaluasi yang direkomendasikan yaitu CIPP.

\section{Evaluasi Context Pendidikan Agama Islam}

Evaluasi program pendidikan untuk mengetahui tingkat pencapaian program sekaligus memberikan tanggung jawab (accountability) program yang telah berjalan dan memberikan informasi untuk pengambilan keputusan pembuat pada tahap perencanaan. (Putra, Evaluation of Learning And Evaluation of Training, 2016). Evaluasi context adalah evaluasi yang digunakan sebagai bahan pertimbangan membuat keputusan perencanaan yang berkaitan dengan lingkungan program yang telah dilaksanakan. Evaluasi kontek sebagai fokus institusi yakni mengidentifikasi target populasi dan 
menilai kebutuhan. Evaluasi konteks memberikan informasi bagi pengambil keputusan dalam perencanaan suatu program yang akan dilaksanakan, analisis ini akan membantu dalam memecahkan keputusan menetapkan kebutuhan dan merumuskan tujuan program secara lebih terarah.

Evaluasi konteks dilaksanakan sebagai need assesment atas suatu kebutuhan, memberikan informasi bagi pengambilan keputusan dalam perencanaan suatu program yang akan dijalankan. Menurut Stufflebeam evaluasi konteks adalah evaluasi yang paling mendasar, yang mempunyai misi untuk menyediakan suatu rasional atau landasan untuk penentuan tujuan pendidikan.

Berdasarkan uraian diatas dapat disimpulkan bahwa evaluasi konteks meliputi analisis masalah yang berhubungan dengan lingkungan program yang dilaksanakan yang secara khusus mempunyai pengaruh terhadap konteks masalah yang menjadi komponen program. Dapat dikatakan pula bahwa evaluasi konteks adalah evaluasi terhadap kebutuhan, yaitu memperkecil kesenjangan antara kondisi faktual dengan kondisi yanng diharapkan. Tujuan utama evaluasi konteks adalah mengidentifikasi kekuatan kelemahan dari sasaran dan memberikan arah dalam perbaikan.

\section{Evaluasi Input Pendidikan Agama Islam}

Evaluasi Input adalah evaluasi yang digunakan sebagai bahan pertimbangan membuat keputusan. Evaluasi masukan meliputi analisis persoalan yang berhubungan dengan bagamana penggunaan sumber-sumber yang tersedia. Evaluasi masukan bermanfaat untuk membimbing pemilihan strategi program dalam menspesifikasi rancangan prosedural. Informasi dan data yang terkumpul dapat digunakan untuk menentukan sumber dan strategi dalam keterbatasan yang ada. Evaluasi input pada penyelenggaraan program pendidikan agama Islam difokuskan pada sosialisasi program, rekruitmen tutor, pengelola, penentuan tempat tutorial dan pelaksanaan tutorial.

Berdasarkan uraian di atas dapat disimpulkan bahwa evaluasi input adalah evaluasi yang memberikan informasi-informasi untuk membawa kearah perubahan yang dibutuhkan dengan mempertimbangkan strategi alternatif program sehingga menghindari pemborosan pada pelaksanaan.

\section{Evaluasi Proses Pendidikan Agama Islam}


Evaluasi proses digunakan sebagai bahan mengimplementasi keputusan dalam kegiatan atau mengidentifikasi kerusakan prosedur implementasi baik tatalaksana kejadian dan aktivitas. Setiap evaluasi dimonitor dan dicatat perubahan-perubahan yang terjadi secara jujur dan cermat, untuk pengmbilan keputusan dalam menentukan tindak lanjut program, serta untuk menentukan kekuatan dan kelemahan, juga mengetahui faktor pendukung dan penghambat ketika dikaitkan dengan temuan.

Dengan demikian, dapat disimpulkan bahwa evaluasi proses adalah pengawasan secara terus menerus pada pelaksanaan program yang sangat berguna dalam menentukan kekuatan atau pendukung dan kelemahan atau hambatan sehingga prosedur dapat dimonitor dan diperbaiki.

\section{Evaluasi Produk Pendidikan Agama Islam}

Evaluasi produk digunakan sebagai bahan pertimbangan penolong keputusan selanjutnya. Merupakan diskripsi dan keputusan dari outcome dan hubungan dengan konteks, masukan dan proses, kemudian di interpretasikan harga dan jasa yang diberikan. Evaluasi produk adalah evaluasi yang dilakukan dalam mengukur keberhasilan pencapaian tujuan yang telah ditetapkan. Evaluasi produk merupakan titik pencapaian hasil dan keputusan untuk perbaikan pelaksanaan atau aktualisasi pengukuran, dikembangkan dan diadministrasikan secara cermat dan teliti, keakuratan analisis data akan menjadi bahan dalam penarikan kesimpulan dan pengajuan saran apakah program dimodifikasi, diteruskan atau dihentikan.

Evaluasi produk merupakan tahap akhir, berfungsi untuk membantu penanggung jawab program dalam mengambil keputusan dalam analisis hasil, diperlukan sebagai perbandingan antara tujuan yang ditetapkan dalam rancangan dengan program yang dicapai. Hasil yang dinilai dapat berupa data observasi, sekor tes, presentasi, diagram data, sosiometri dan sebagainya.

Berdasarkan uraian diatas, dapat disimpulkan bahwa evaluasi produk adalah evaluasi yang digunakan sebagai bahan pertimbangan membantu keputusan. Selanjutnya dengan mengumpulkan deskripsi dan penilaian hasil serta menghubungkannya dengan sasaran dan konteks, input dan proses sehingga dapat diinterpretasikan nilai dan manfaat. 


\section{Kesimpulan}

Berdasarkan pembahasan di atas dapat disimpulkan sebagai berikut: 1) Penilaian konteks pada pendidikan agama islam meliputi beberapa aspek seperti: latar belakang program sekolah, faktor geografis, demografis, latar belakang pendidikan pendidik dan pembelajaran pendidikan Agama Islam. Informasi yang dikumpulkan digunakan sebagai dasar dalam pertimbangan program. 2) Penilaian input meliputi pendidik, bahan ajar, serta sarana prasarana pendidikan Agama Islam. 3) Penilaian proses merupakan kegiatan penilaian selama pelaksanaan kegiatan. Penilaian ini berkaitan langsung dengan pelaksanaan aktivitas pembelajaran, penggunaan media pembelajaran, kemanfaatan, , fasilitas pendidikan Agama Islam. Dan 4) Penilaian produk, berhubungan dengan hasil pelaksanaan program pendidikan Agama Islam. Penilaian dilakukan untuk mengetahui sampai seberapa jauh pelaksanaan program pendidikan agama Islam telah berhasil mencapai tujuan berdasarkan kriteria yang ditetapkan.

\section{DAFTAR PUSTAKA}

Brinkerhoff, R. O. (1983). Program Evaluation A Practutioner's Guide For Trainers and Educators. Boston: Kluwer Nijhoff Publishing.

Daniel L Stufflebeam, A. J. (2007). Evaluation Theory, Models, \& Applications. San Francisco: Jossey-Bass.

Djaali, M. (2004). Pengukuran dalam Bidang Pendidikan. Jakarta: Program Pascasarjana.

Egon G Guba, Y. S. (1983). Effective Evaluation, Improving the usefulness of Evaluation Results Through Responsive and Naturalistic Approaches . San Francisco: Jossey Bass Publishe.

Evaluation, J. C. (1994). The Program Evaluation Standard. California: Sage Publication.

George F. Madaus, M. S. (1985). Evaluation Model, Viewpoints on Educational and Human Services Evaluation. Boston: Kluwer Nijhoff Publishing.

Leonora Layola Oriondo, E. M. (1998). Evaluating Educational Outcomes. Manila: Rex Book Store.

Musa, S. (2005). Evaluasi Program Pembelajaran dan Pemberdayaan Masyarakat. Bandung: Y-Pin Indonesia.

Nasional, D. P. (2009). Evaluasi Program Sekolah. Yogyakarta: Universitas Negeri Yogyakarta.

Norman E. Groundlund, R. L. (1990). Measurement and Evaluation in Teaching. New York: MacMillan Publishing Company.

Popham, W. J. (1974). Educational Evaluation. New Jersey: Prentice Hall. Inc.

Popham, W. J. (1981). Modern Educational Evaluation. New Jersey: Prentice Hall Inc. 
Putra, A. T. (2012). Evaluasi Program Pendidikan:"Pedekatan Evaluasi Program Berorientasi Tujuan (Goal-Oriented Evaluation Approach: Ralph W. Tyler)”. Shautut Tarbiyah, 1.

Putra, A. T. (2016). Evaluation of Learning And Evaluation of Training. Langkawi, 176.

Rutman, L. (1984). Evaluation Research Methodology. New Delhi: Sage Publishing India PUT Ltd.

Suharsimi Arikunto, C. S. (2004). Evaluasi Program Pendidikan. Jakarta: Bumi Aksara.

Suparman M. Atwi, Z. A. (2004). Pendidikan Jarak Jauh Teori dan Praktek. Jakarta: Universitas Terbuka.

Syah, M. (1995). Psikologi Pendidikan dengan Pendekatan Baru . Jakarta.

Syah, M. (1995). Psikologi Pendidikan dengan Pendekatan Baru . Bandung: Remaja Rosda Karya.

Tasner, M. (1995). Planning and Conductioning Formative Evaluation. London: Kogan Page.

Tayibnapis, F. Y. (2008). Evaluasi Program dan Instrumen Evaluasi. Jakarta : PT Rineka Cipta.

Thorndike R.L, E. H. (1991). Measurement and Evaluation in Psychology and Education. New York: MacMillan Publishing Company.

Toha, M. C. (1991). Teknik Evaluasi Pendidikan. Jakarta : PT. Raja Grafindo Persada. 